\title{
Characterization of the distribution of water vapour for DInSAR studies on the volcanic island of Tenerife, Canary Islands
}

\author{
Antonio Eff-Darwich ${ }^{\text {a,c }}$, Begoña García-Lorenzo ${ }^{\mathrm{a}, \mathrm{b}}$, Juan C. Pérez-Darias ${ }^{\mathrm{d}}$, Albano González ${ }^{\mathrm{d}}$, \\ José Fernández ${ }^{\mathrm{e}}$, Pablo J. González ${ }^{\mathrm{e}}$ \\ ${ }^{a}$ Instituto de Astrofísica de Canarias, E-38200-La Laguna, Tenerife, Spain \\ ${ }^{b}$ Departamento de Astrofísica, Universidad de La Laguna, E-38205 La Laguna, Tenerife, Spain \\ 'Departamento de Edafología y Geología, Universidad de La Laguna, E-38205 La Laguna, Tenerife, \\ Spain \\ ${ }^{d}$ Departamento de Física Fundamental y Experimental, Electrónica y Sistemas, Universidad de La \\ Laguna, E-38205, La Laguna, Tenerife, Spain \\ eInstituto de Astronomía y Geodesia, CSIC-UCM, Fac. C. Matemáticas, Plaza de Ciencias, 3, 28040- \\ Madrid, Spain
}

\begin{abstract}
Measurements of ground displacement have been carried out on the entire active volcanic island of Tenerife, Canary Islands, by means of classical and advanced DInSAR techniques. The main limiting factor on the accuracy of DInSAR measurements is the distribution of the water vapour in the lower troposphere. Hence, it is yet necessary to perform a detailed spatial and temporal characterization of water vapour to understand, and to be able to carry out a direct computation of, the effect of the tropospheric delay on DInSAR results. In this sense, satellite and balloon data have been analysed to infer the variability in the distribution of water vapour and hence, the robustness of DInSAR results on the island of Tenerife.
\end{abstract}

Keywords: DInSAR, volcanoes, Tenerife, water vapour

\section{INTRODUCTION}

Geodetic techniques are being used extensively at active volcanoes and have provided useful eruption precursors (e.g., Dvorak and Dzurisin, 1997; Dzurisin, 2007). Geodetic signals can play a key role in early detection of volcanic unrest due to the very high precision attainable with present-day techniques and instruments. In the last decades, several observational and theoretical studies have been carried out in the context of geodetic monitoring in the volcanic island of Tenerife. A 17-benchmark classical geodetic network and a levelling profile located in the area of Las Cañadas Caldera (see Fig. 1) have been observed several times since 1982. No displacements were found from 1982 to 2000 during the observation of both the geodetic network and the levelling profile (Fernández et al. 2003). Theoretical analysis carried out by Yu et al. (2000) and Eff-Darwich et al. (2008a) demonstrated the need to extend the existing geodetic network in Las Cañadas Caldera to cover the full island for volcano monitoring purposes.

Ground displacement analyses have been carried out on the entire island by means of classical DInSAR techniques and complemented by GPS from 1992 to 2008 (Fernández et al., 2003, 2004, 2005, 2009). Fernández et al. (2009) used the SBAS DInSAR algorithm (Berardino et al. 2002; Lanari et al. 2007) to process 55 radar images acquired from descending orbits by the ERS-1/2 satellites during 1992-2005. SBAS technique assumes that atmospheric inhomogeneities between acquisition pairs are space correlated, but temporal uncorrelated. Therefore, SBAS removes the atmospheric phase signal component applying a cascade of high-pass spatial filters and a low-pass temporal filter. The filter includes also the compensation for the topography correlated atmospheric phase artefacts. They found four funnel-shaped areas with high displacement rates. The first one (located in the area labelled "a" in Figure 2), which has

* adarwich@iac.es; phone +34 922605 200; fax +34 922605210

Remote Sensing for Environmental Monitoring, GIS Applications, and Geology IX, edited by Ulrich Michel, Daniel L. Civco, Proc. of SPIE Vol. 7478, 747804 · @ 2009 SPIE · CCC code: 0277-786X/09/\$18 · doi: 10.1117/12.830340 
the largest magnitude, affects an area of $15 \mathrm{~km}^{2}$ with a deformation rate of about $15 \mathrm{~mm} / \mathrm{year}$. The second area, labeled " $\mathrm{b}$ " in Figure 2, extends over $8 \mathrm{~km}^{2}$ and a deformation rate of about 5-6 mm/year. The third zone ("c" label in Figure 2) has a deformation rate of $3 \mathrm{~mm} / \mathrm{year}$, whereas the last analyzed deformation (" $\mathrm{d}$ " label in Figure 2) shows a deformation rate of about $3 \mathrm{~mm} /$ year. Their analysis also reveals that the summit area of the volcanic edifice is characterized by a continuous subsidence extending well beyond Las Cañadas caldera rim and corresponding to the dense core of the island. These results, coupled with GPS ones, structural and geological information and deformation modelling, suggest that the intrusive complex is subsiding into a weak lithosphere and that the volcanic edifice is in a state of compression (Fernández et al., 2009).

Due to the unpredictable character of atmospheric phase delays it has until recently been difficult to separate atmospheric delays from the effects of deformation and topography without external data on the atmospheric water vapour content such as measurements provided by radio-soundings or permanent GPS arrays (Webley et al., 2002; Li et al., 2006). Recently, it has been suggested the use of atmospheric remote sensing data to correct the DInSAR results (Li et al., 2005; Puyssegur et al., 2007). Here, we used the Moderate Resolution Imaging Spectro-radiometer (MODIS) instrument to estimate the atmospheric water vapour content for InSAR correction on Tenerife, we analyzed the expected tropospheric phase delays calculated from MODIS and compared them (in a first approximation) with the crustal deformation patterns already found on the island by InSAR.

\section{GEOLOGICAL SETTING}

Tenerife is the largest island of the Canarian Archipelago and one of the largest volcanic islands in the world. It is located between latitudes $28-29^{\circ} \mathrm{N}$ and longitudes $16-17^{\circ} \mathrm{W}, 280 \mathrm{~km}$ distant from the African coast. It conforms an active volcanic region, its age varying from Middle Miocene to present, with no evidence of important gaps in its volcanic activity history, at least in the last 3 to $4 \mathrm{Ma}$ (Ancochea et al., 1990). This activity is still evident in stationary low temperature fumarolic activity at Teide crater $\left(<85^{\circ} \mathrm{C}\right)$, diffusive gaseous emissions, groundwater temperatures reaching up to $50^{\circ} \mathrm{C}$ and volcanic contamination of groundwater in the subsurface of the central region (Eff-Darwich et al. 2008b).

The morphology of Tenerife (see Fig. 1) is the result of a complex geological evolution: the subaerial part of the island was originally constructed by fissural eruptions of ankaramite, basanite and alkali basalts that occurred between 12 and 3.3 Ma (Ancochea et al. 1990). These formations made up shield volcanoes that remain at present as three eroded massifs occupying the three corners of the island (Teno, Anaga and Roques del Conde massifs). In the central part of the island, from 3.5 Ma to present, the emission of basalts and differentiated volcanics gave rise to a large central volcanic complex, the Las Cañadas Edifice (Martí et al, 1994). After a period of mafic volcanism, several periods of phonolitic activity took place, culminating in the formation of a large elliptical depression measuring $16 \times 9 \mathrm{~km}^{2}$, known as Las Cañadas Caldera. In the northern sector of the caldera, the Teide-Pico Viejo complex was constructed as the product of the most recent phase of central volcanism. Teide-Pico Viejo is a large stratovolcano that has grown during the last 175 Ky. The post-shield basaltic activity, which overlaps the Las Cañadas Edifice, is mainly found on two ridges (NE and NW), which converge on the central part of the island (Ancochea et al. 1990). Large scale lateral collapses, involving rapid mass movements of hundreds of cubic kilometres of rock, are responsible for the formation of three valleys: La Orotava, Güimar and Icod. Recorded eruptive activity has consisted of six strombolian eruptions, namely Siete Fuentes (1704), Fasnia (1705), Arafo (1705), Arenas Negras (1706), Chahorra (1798) and Chinyero (1909). The last three eruptions occurred at the NW ridge system, the most active area of the island together with El Teide-Pico Viejo Edifice for the last 50,000 years (Carracedo et al. 2003).

We carried out a theoretical analysis in order to study the approximated spatial extend of crustal deformation associated to volcano-tectonic processes in Tenerife, namely activity associated to a magma chamber, a dike injection and a dislocation induced by a fault. The first case we studied was the ground deformation associated to a reactivation in the magmatic system associated to El Teide- Pico Viejo stratovolcano. Following Fernández et al. (1997) and Eff-Darwich et al. (2008b), we considered a spherical intrusion at 6 kilometres depth and $P a^{3}=10^{4} \mathrm{MPa} / \mathrm{km}^{3}$, being $P$ and $a$ the pressure and radius of the magma intrusion. Vertical displacements of at least $1 \mathrm{~cm}$ extend more than $15 \mathrm{~km}$ from the volcano, as illustrated in Fig. 2.

The second case of the theoretical analysis corresponds to the other possible kind of magmatic intrusion in Tenerife, namely dikes (Yu et al., 2000). To explain the observed ground deformation, we use the conventional assumption of dislocations buried in an elastic half space composed of a Poisson solid, as illustrated by Feigl and Dupré (1999). These 
authors developed the numerical code RNGCHN that was used to calculate the ground deformation due to dike intrusion. Fig. 2 shows the effects produced by a vertical dike located in the NE ridge, extending from the mantle (about $25 \mathrm{~km}$ depth) to $0.2 \mathrm{~km}$ depth, having a length of $4 \mathrm{~km}$ and a thickness of $1 \mathrm{~m}$. The vertical displacement of at least $1 \mathrm{~cm}$ extends over a large portion of the island.

The third case in our theoretical analysis is represented by a dislocation induced by a fault (see Fig. 2). Following Feigl and Dupré (1999), and considering the major submarine fault parallel to the eastern coast of Tenerife (as illustrated in Fig. 2), we calculated the vertical displacement associated to a $45 \mathrm{~km}$ long fault dipping $60^{\circ}$ and extending from $25 \mathrm{~km}$ below the surface to a depth of $35 \mathrm{~km}$ with $10 \mathrm{~cm}$ of dip-slip.

\section{METHODOLOGY AND DATA}

We attempt to understand the effect of tropospheric water content on the determination of crustal deformation through radar interferometry on the island of Tenerife. It is thus necessary to calculate the spatial and temporal distribution of water vapour on the island and the theoretical slant phase delay induced by the water vapour on radar interferometric data.

We first investigated the expected distribution of water vapour, hence a subset of the MODIS Near Infrared Total Water Vapour Product images. The Total Precipitable Water is a measure of the total amount of water vapor in a column of air and can be used to infer precipitation amounts. Usually it is measured in centimeters or millimeters. Various precipitable water products have been developed and are available operationally for assessing the state of the atmosphere with respect to the magnitude of the moisture and its transport. MODIS, onboard Terra and Aqua satellites, views the earth every 1 to 2 days. It is thus well suited for global monitoring of atmospheric properties from space. Moreover, it acquires data in 36 spectral bands, from 0.4 to $14.0 \mu \mathrm{m}$ with spatial resolutions ranging from $250 \mathrm{~m}$ to $1 \mathrm{~km}$. Data acquired are then processed to generate several level 2 and 3 land, ocean and atmosphere products. Among them, we selected the "MODIS Precipitable Water" product (PWV) that can be retrieved at each satellite pass with a spatial resolution of $1 \mathrm{~km}$ and an accuracy of 5\% to $10 \%$ (Gao \& Kaufman, 2003). In this work, a set of MODIS-PWV images acquired for a two year period (2006-2007) are analyzed

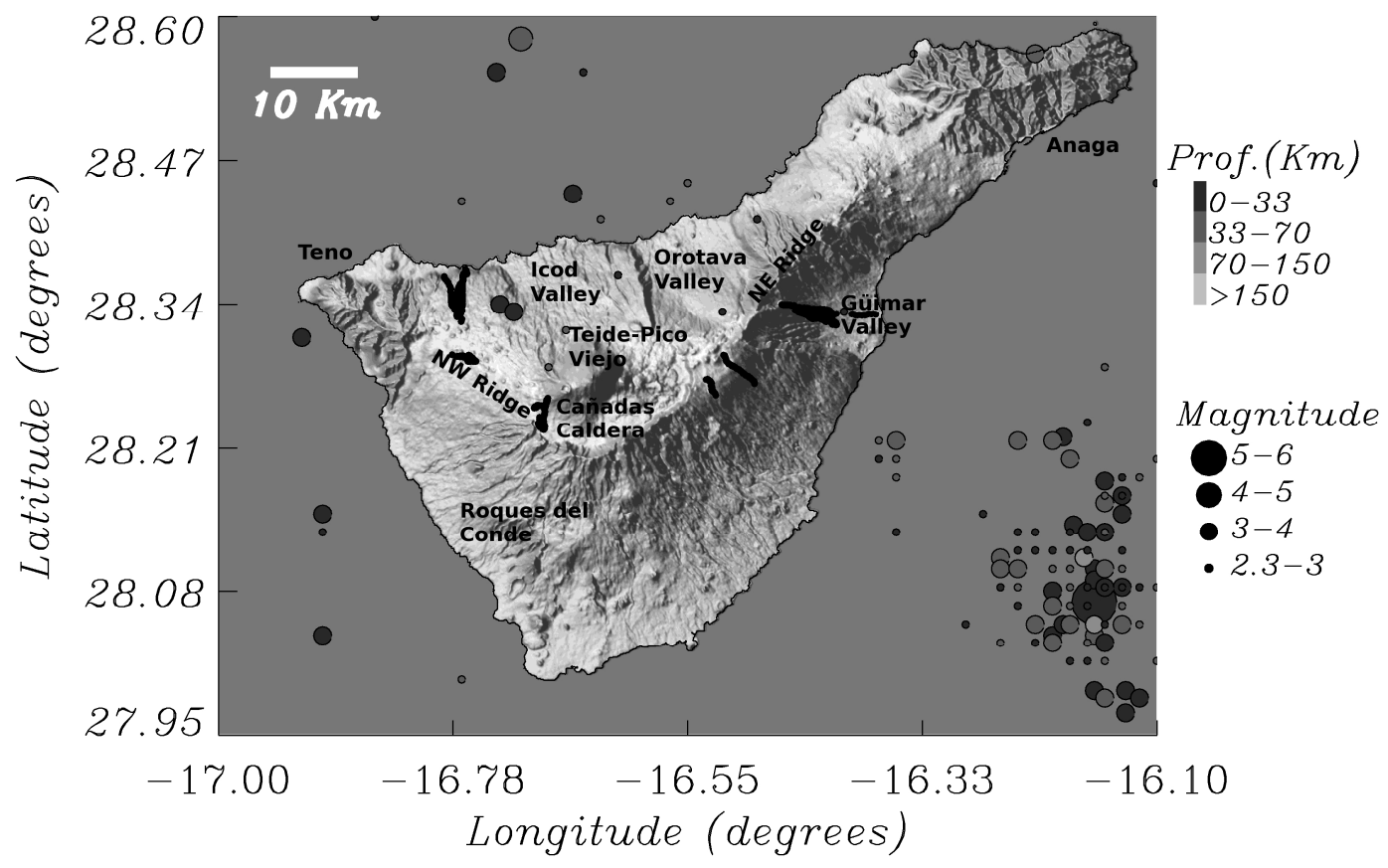

Figure 1: Shaded-relief map of the island of Tenerife. Filled circles of different colors represent the location of earthquakes registered in and around Tenerife from 1993 to 2008, whereas the black-filled areas represent the extension of the historical eruptions (last 500 years). 
Once the PWV data are obtained, it is necessary to calculate the spurious signal that water vapour introduces in the crustal deformation maps obtained by DInSAR. The slant phase delay induced by the presence of atmospheric water vapour may be approximated following the equation proposed by Hanssen (2001):

$$
\Phi_{p, q}=\frac{4 \pi \Pi^{-1} \Delta_{P W V}}{\lambda \cos \left(\theta_{i n c}\right)}
$$

where $\Phi_{p, q}$ (radians) represents the predicted interferometric phase difference between pixel $\mathrm{p}$ and $\mathrm{q}$, $\Pi$ is a constant factor, $\Delta_{\mathrm{PWV}}(\mathrm{mm})$ the precipitable water column obtained by MODIS, $\lambda(\mathrm{mm})$ is the radar wavelength and $\cos \left(\theta_{\text {inc }}\right)$ is the cosine of the incidence angle of the satellite taking the radar images. Considering a typical parameter set of $\Pi \approx 0.15$ (Bevis et al., 1996) and $\theta_{\text {inc }}=30^{\circ}$, it is expected that up to $7.5 \Delta_{\mathrm{PWV}}(\mathrm{mm})$ of the signal in the interferometric images are due to the phase delay resulting from the presence of water vapour in the troposphere.

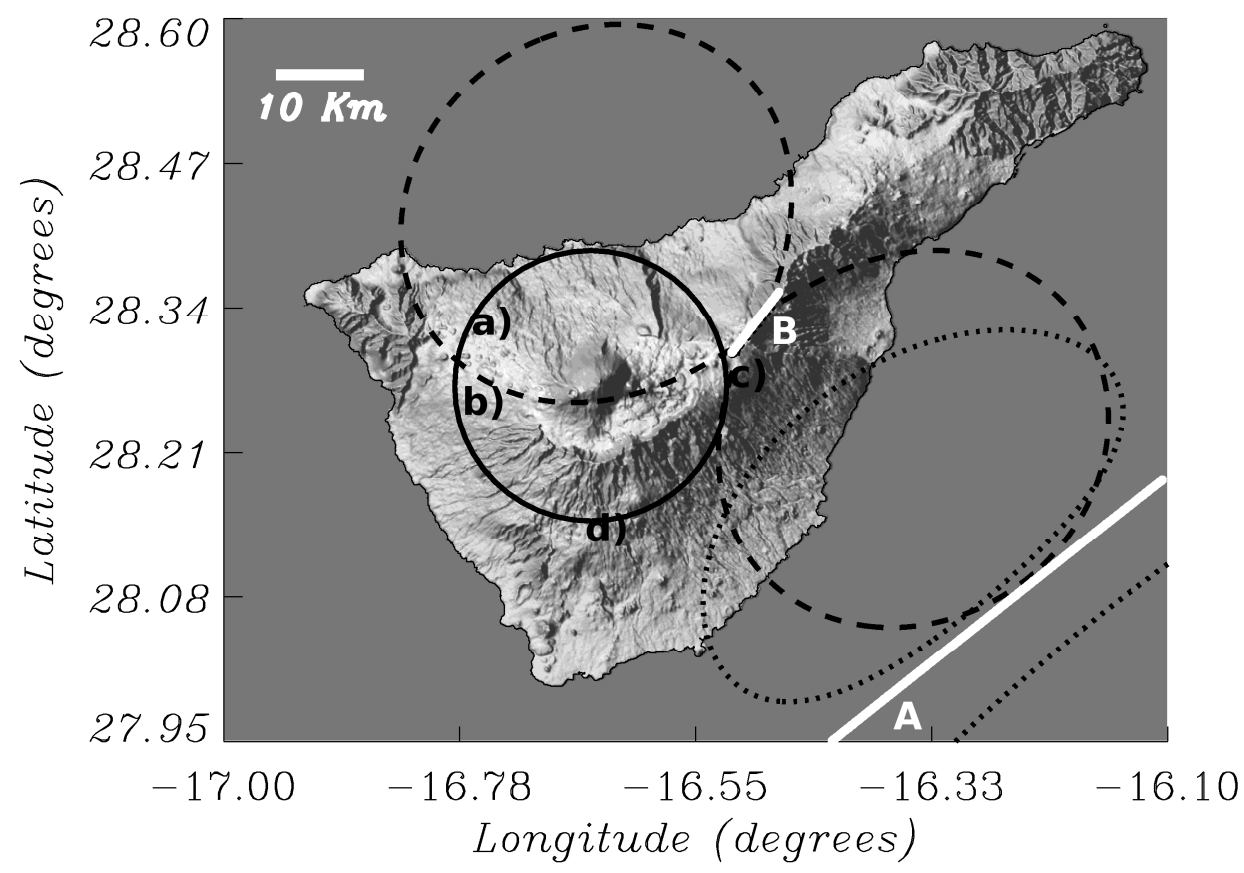

Figure 2: Areas affected by at least $1 \mathrm{~cm}$ of vertical displacement as the result of a dike intrusion (dashed lines), a magma chamber reactivation (solid lines) and a fault (dotted lines). The surface projection of the dike and the fault are represented by white solid lines, labeled A and B, respectively. The location of local crustal deformation areas detected in Tenerife by means of DinSAR are marked as a), b), c) and d). See text for details.

\section{RESULTS AND CONCLUSIONS}

The annual mean and the corresponding annual standard deviation of the MODIS-based PWV for the years 2006 and 2007 are presented in Figs. 3 and 4, respectively. PWV results obtained from MODIS agree with those obtained by balloon soundings launched from Güimar Meteorological Station (105 m.a.s.l, station 60018 of the National Oceanic and Atmospheric Admisnistration operated by the Spanish Agencia Estatal de Meteorología and available through the University of Wyoming server ${ }^{1}$ ), as illustrated in Fig. 6. As expected, the most prominent feature is the systematic decrease in PWV with altitude, being Las Cañadas Caldera the area with the lowest content of precipitable water. The standard deviation maps also show that the PWV variations decrease with altitude. If the time variation of PWV is

$1 \underline{\mathrm{http}} / / /$ weather.uwyo.edu/upperair/sounding.html 
calculated for the dates radar images were acquired, as illustrated for the Güimar station in Fig. 7, it is possible to analyze at a small spatial scale the effect of PWV on crustal deformation inferences. In this case, the relative stable and small PWV contents for the years 2002 and 2003 turn into unstable and large PWV contents in 2004 and 2005. These significant variations could introduce spurious signals in the crustal deformation images that should be analyzed in detail.

In the areas where crustal deformations have been detected by DInSAR (see Fig. 2), temporal changes of PWV expressed as $1 \sigma(\sigma$ being the standard deviation) could reach up to $5 \mathrm{~mm}$, hence applying equation (1) $1 \sigma$ spurious crustal deformation in radar interferometric data might reach up to $3.75 \mathrm{~cm}$. In this sense, the $1 \sigma$ spurious signal in DInSAR results associated to tropospheric water vapour during the winter season reaches $2.2 \mathrm{~cm}$. Both annual means and standard deviations of PWV are seasonal-dependent, being lowest in the winter and highest in the summer (as illustrated in Fig. 5). These results look consistent with the conclusions by Fernández et al. (2009).

The spatial and temporal distribution of water vapour above the island of Tenerife implies that if DInSAR data are not corrected by PWV, crustal deformation are statistically significant $(>1 \sigma)$ if

$$
\mathrm{T} \Delta \delta>37.5
$$

being $\mathrm{T}$ (years) the time span of radar data and $\Delta \delta(\mathrm{mm} / \mathrm{year})$ the crustal deformation rate. Hence, if we do not correct by the effect of PWV, the crustal deformations detected in Tenerife should be statistically significant after 10 years of DiNSAR observations for areas b), c) and d) (see Fig. 2) and 3 years of DInSAR observations in area a).

Some statistical techniques may be applied to correct interferometric data from atmospheric effects. These techniques are based on the differences, both in time and space, between crustal deformation patterns and the distribution of water vapour in the atmosphere (Atzori et al. 2008). In this sense, Fernández et al. (2009) used the SBAS (Berardino et al. 2002) to compensate from atmospheric effects on SAR interferometric data. Accordingly, these undesired signals are identified via the cascade of a low-pass filtering, carried out in the two-dimensional spatial domain, followed by a temporal high-pass filtering. However, the annual mean and standard deviation PWV maps corresponding to 2006 and 2007 (Figs. 3, 4 and 5) indicate that the spatial distribution of PWV might be poorly correlated at kilometer scales. Therefore, it should be interesting to compare the results obtained using both methodologies for atmospheric effects correction, SBAS-like atmospheric filtering and direct computation of the effect, in Tenerife considering SAR and atmospheric data for the same time period.

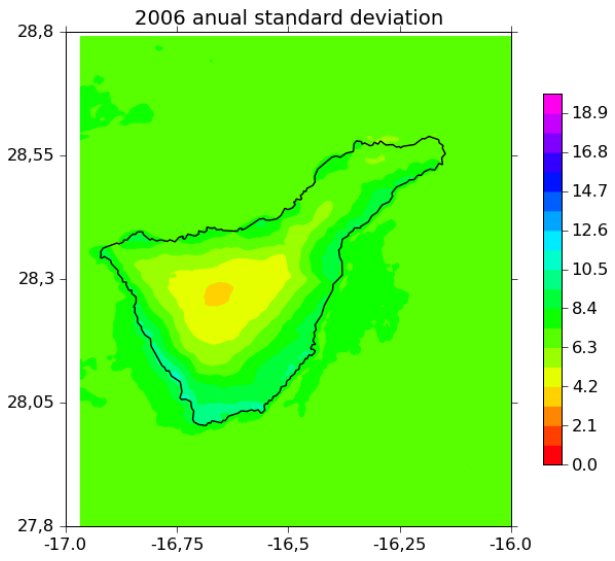

(A)

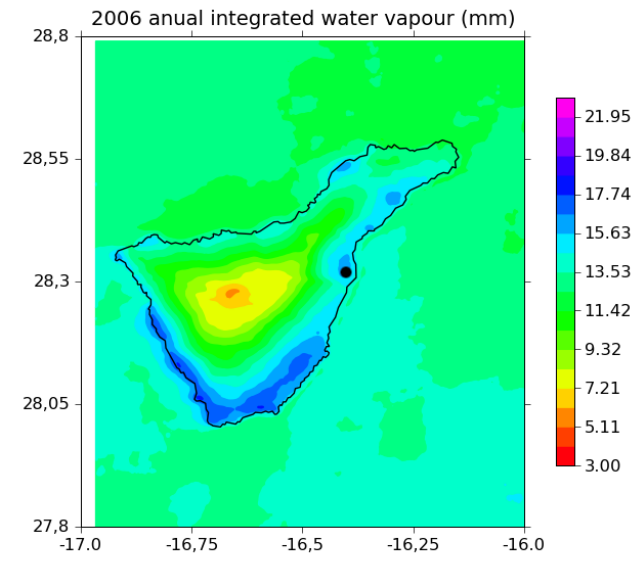

(B)

Figure 3: (A) Annual mean corresponding to 2006 for the MODIS-based Precipitable Water Vapour (PWV) content. (B) Spatial distribution of the standard deviation calculated from the PWV annual mean corresponding to 2006. Blackfilled circle marks the location of the balloon launching station at Güimar. 


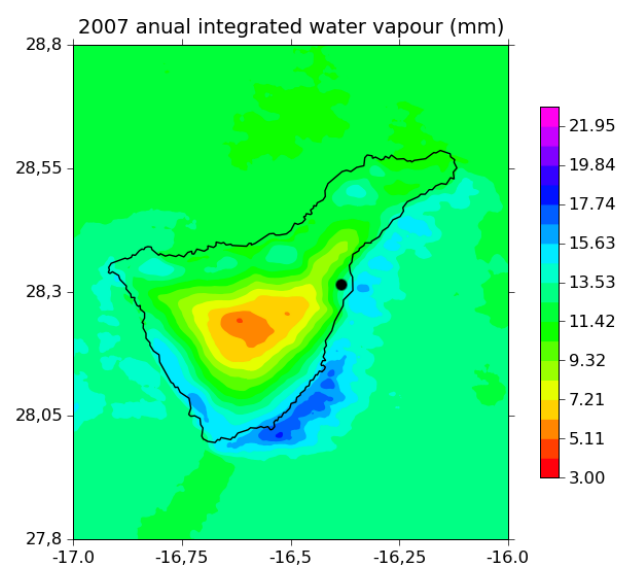

(A)

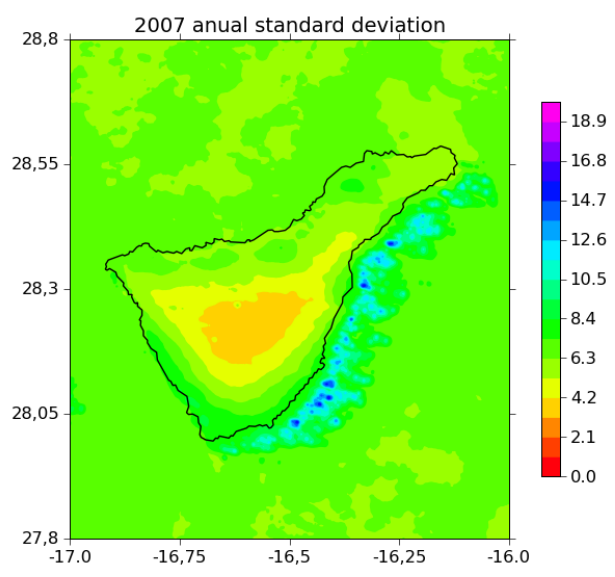

(B)

Figure 4: (A) Annual mean corresponding to 2007 for the MODIS-based Precipitable Water Vapour (PWV) content. Blackfilled circle marks the location of the balloon launching station at Güimar. (B) Spatial distribution of the standard deviation calculated from the PWV annual mean corresponding to 2007.

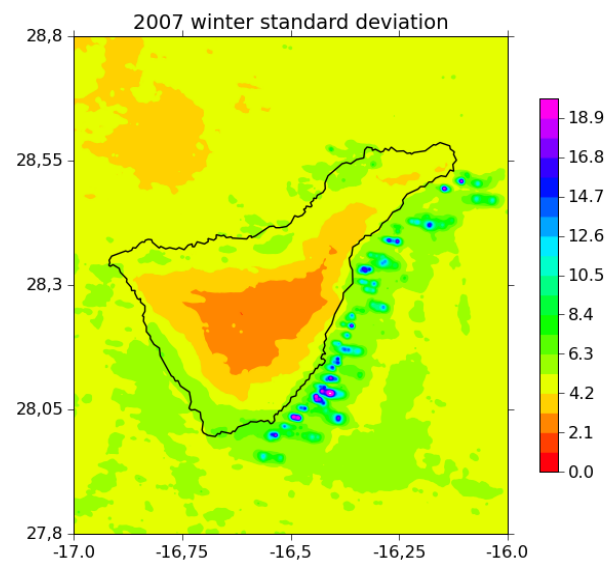

(A)

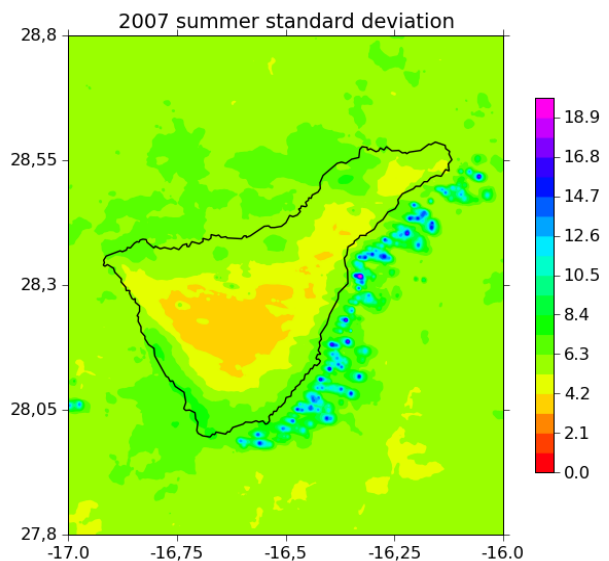

(B)

Figure 5: (Upper panel) Spatial distribution of the standard deviation calculated from the PWV mean corresponding to the winter of 2007. (Lower panel) Spatial distribution of the standard deviation calculated from the PWV mean corresponding to the summer of 2007.

Understanding the distribution in time and space of tropospheric water vapour is thus necessary to characterize crustal deformation in Tenerife through SAR interferometric data. This is important in the case of Tenerife, where ground deformation induced by geological activity might extend over larger portions of the island (see Fig. 2), but magnitude of displacements are only of a few centimeters and hence, spatial coherence in interferometric SAR images are required.

The results of this work are based on a simplistic atmospheric model used to derive equation (1). Moreover, the time span of MODIS data is short. In any case, these results give a good idea on the complexity of the distribution (both spatial and temporal) of water vapour over the island of Tenerife and the likely effect of PWV on the crustal deformation maps obtained by interferometric radar imaging. Future work extending MODIS data analysis is thus necessary. Moreover, more detailed studies considering same time period for atmospheric and SAR data will be done, considering classical and advanced DInSAR techniques for correction, validation and comparison 


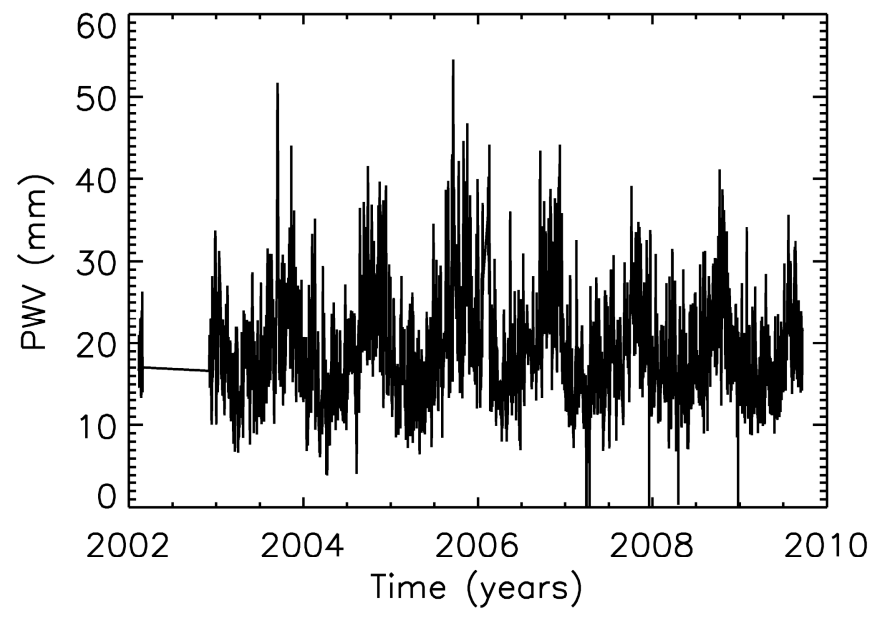

Figure 6: Temporal distribution of Precipitable Water Vapour (PWV) obtained by balloon soundings launched from Güimar Station, Tenerife for the period 2002 to 2009.

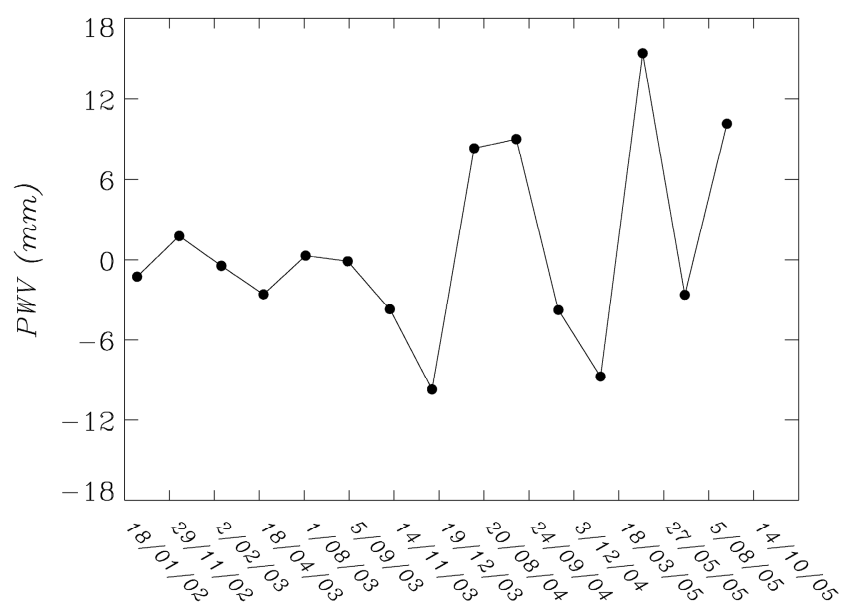

Figure 7: Time variation of PWV obtained by balloon soundings at Güimar station for the same dates DiNSAR data were collected.

\section{REFERENCES}

1. Ancochea, E., Fúster, J.M., Ibarrola, E., Cendrero, A., Coello, J., Hernán, F., Cantagrel, J.M., and Jamond, A., "Volcanic evolution of the island of Tenerife (Canary Islands) in the light of new K-Ar data", J. Volcanol. Geotherm. Res. 44, 231-249 (1990)

2. Atzori, S., Manunta, M., Fornaro, G., Ganas, A., and Salvi, S., "Postseismic displacement of the 1999 Athens earthquake retrieved by the Differential Interferometry by Synthetic Aperture Radar time series", J. Geophys. Res., 113, B09309 (2008)

3. Berardino, P., Fornaro, A., Lanari, R., and Sansosti, E., "A new algorithm for surface deformation monitoring based on small baseline differential SAR interferograms", IEEE Trans. Geosci. Remote Sens., 40(11), 2375 - 2383 (2002)

4. Bevis, M., Chiswell, S., Businger, S., Herring, T. and Bock, Y., "Estimating wet delays using numerical weather analysis and predictions". Radio Science 31(3), pp. 447-487 (1996) 
5. Carracedo, J.C., Paterne, M., Guillou, H., Perez Torrado, F.J., Paris, R., Rodriguez Badiola, E., and Hansen, A., "Dataciones radiometricas (C14 y K/Ar) del. Teide y el rift noroeste, Tenerife, Islas Canarias", Estudios Geol. 59, 15-29 (2003)

6. Dvorak, J.J., and Dzurisin, D., "Volcano geodesy; the search for magma reservoirs and the formation of eruptive event". Reviews of Geophysics 35, 343-384 (1997)

7. Dzurisin D., [Volcano deformation: New geodetic monitoring techniques], Springer-Verlach, Berlin Heilderberg New York, 51-68 and 89-95 (2007)

8. Eff-Darwich, A., Grassin, O. And Fernández, J., "An Upper Limit to Ground Deformation in the Island of Tenerife, Canary Islands, for the Period 1997 2006", Pure and Applied Geophysics, 165, 1049 (2008a)

9. Eff-Darwich, A., Coello, J., Viñas, R., Soler, V., Martin-Luis, M. C., Farrujia, I., Quesada, M. L.and De La Nuez, J., "Underground Temperature Measurements as a Tool for Volcanic Activity Monitoring in the Island of Tenerife, Canary Islands", Pure and Applied Geophysics, 165, 135 (2008b)

10. Feigl, K.L., and Dupré, E., "RNGCHN: A Program to calculate displacement components from dislocations in an elastic half-space with applications for modeling geodetic measurements of crustal deformation", Computers and Geosciences 25, 695-704 (1999)

11. Fernández, J., Yu, T.-T., Rodríguez-Velasco, G., González-Matesanz, J., Romero, R., Rodríguez, G., Quirós, R., Dalda, A., Aparicio, A., and Blanco, M.J., "New geodetic monitoring system in the volcanic island of Tenerife, Canaries, Spain. Combination of InSAR and GPS techniques". J. Volcanol. Geotherm. Res. 124/3-4, 241-253 (2003)

12. Fernández, J., González-Matesanz, F. J., Prieto, J. F., Staller, A., Rodríguez-Velasco, G., Alonso-Medina, A., Charco, M., "GPS Monitoring in the N-W part of the Volcanic Island of Tenerife, Canaries, Spain. Strategy and results", Pure and Applied Geophysics, 161, 1359-1377 (2004)

13. Fernández, J., Romero, R.; Carrasco, D., Tiampo, K.F., Rodríguez-Velasco, G., Aparicio, A., Araña, V., GonzálezMatesanz, F.J., "Detection of displacements in Tenerife Island, Canaries, using radar interferometry", Geophysical Journal International, 160, 33-45 (2005)

14. Fernández, J., Tizzani, P., Manzo, M., Borgia, A., González, P. J., Martí, J., Pepe, A., Camacho, A. G., Casu, F., Berardino, P., Prieto, J. F. and Lanari, R., "Gravity-driven deformation of Tenerife measured by InSAR time series analysis", Geophys. Res. Lett., 36, L04306 (2009)

15. Gao, B. C., and Kaufman, Y.J., "Water vapor retrievals using Moderate Resolution Imaging Spectroradiometer (MODIS) near-infrared channels". J. Geophys. Res., Vol. 108, No. D13, 4389 (2003)

16. Hanssen, R., [Radar Interferometry: Data Interpretation and Error Analysis.] Vol. 2, 1 edn, Kluwer Academic Publishers. 1, 20 (2001)

17. Lanari, R., Casu, F., Manzo, M., Zeni, G., Berardino, P., Manunta, M., and Pepe, A., "An Overview of the Small BAseline Subset Algorithm: a DInSAR Technique for Surface Deformation Analysis", Pure and Applied Geophysics, 164, 637-661 (2007)

18. Li, Z., Muller, J.P., Cross, P., "Interferometric synthetic aperture radar (InSAR) atmospheric correction: GPS and Moderate Resolution Imaging Spectrometer (MODIS), and InSAR integration”, J. Geophys. Res., 110 (D20), 4651 (2005)

19. Li, Z., Fielding, E.J., Muller, J.P., Cross, P., "Interferometric synthetic aperture radar atmospheric corrections: GPS topography-dependent turbulent model", J. Geophys. Res. (2006)

20. Martí, J., Mitjavila, J., and Araña, V., "Stratigraphy, structure and geomorphology of the Las Cañadas Caldera (Tenerife, Canary Islands)", Geol. Mag. 131, 715-727 (1994)

21. Puyssegur, B., Michel, R., Avouc, J.P., "Tropospheric phase delay in InSAR estimated from meteorological model and multispectral imaginery", J. Geophys. Res., 112, 7166-7174 (2007)

22. Webley, P.W., Bingley, R.M., Dodson, A.H., Wadge, G., Waugh, S.J., James, I.N., "Atmospheric water vapour correction to InSAR surface motion measurements on mountains: results from a dense GPS network on Mount Etna", Phys. Chem. Earth, 27, 363-370 (2002)

23. Yu, T. T., Fernández, J., Tseng, C.L., Sevilla, M.J., and Araña, V., "Sensitivity test of the geodetic network in Las Cañadas Caldera, Tenerife, for volcano monitoring”, J. Volcanol. Geotherm. Res. 103, 393-407 (2000) 